\title{
Free-Response Self-Discrepancies Across, Among, and Within FFM Personality Dimensions
}

\author{
Adam R. Hafdahl \\ A. T. Panter \\ University of North Carolina at Chapel Hill
}

\author{
Richard H. Gramzow \\ Constantine Sedikides \\ University of Southampton, England, UK
}

\section{Chester A. Insko \\ University of North Carolina at Chapel Hill}

\begin{abstract}
Much of these data were collected for a study described more fully in Gramzow, Sedikides, Panter, and Insko (in press). Portions of this report are based on the first author's Master's thesis conducted under the second author's direction. Research related to this report was presented at the American Psychological Association meetings in Chicago, Illinois, 15-19 August, 1997; the Society of Southeastern Social Psychologists conference in Research Triangle Park, North Carolina, 1 November, 1997; and the American Psychological Association meetings in San Francisco, California, 14-18 August, 1998. We gratefully acknowledge W. Grant Dahlstrom, David Flora, Jack Vevea, and Yiu-Fai Yung for their insightful feedback and suggestions. Sammy Banawan, Simon Kim, Becky Kizakevich, Viji Sathy, Kimberly Swygert, David Weinman, Wendy Yang, and Laurie Zografos contributed invaluable judging assistance.

Correspondence concerning this article should be addressed to Adam R. Hafdahl, Department of Psychology, CB \#3270, Davie Hall, University of North Carolina, Chapel Hill, North Carolina 27599-3270; electronic mail may be sent via Internet to ahafdahl@email.unc.edu
\end{abstract}

Journal of Personality 68:1, February 2000.

Copyright (C 2000 by Blackwell Publishers, 350 Main Street, Malden, MA 02148, USA, and 108 Cowley Road, Oxford, OX4 1JF, UK. 
ABSTRACT An approach for personality-based self-discrepancy (PBSD) measurement is proposed, whereby self-beliefs and incongruities among their contents are assessed with respect to five-factor model (FFM) semantic dimensions. Selves Questionnaire attributes from 191 college students were coded against L. R. Goldberg's (1990) FFM factor analysis to construct personality scores for actual, ideal, and ought self domains, as well as several PBSD indices. Multivariate analyses were conducted to test self-discrepancy and personalitystructure hypotheses, and to demonstrate this strategy's operational flexibility. Profile analyses indicated that empirical self-discrepancies depend upon whether and how personality structure is incorporated. Methodological alterations influenced self-discrepancy findings negligibly. Initial evidence for PBSD construct validity and predictive specificity is presented, and the approach's implications, advantages, and extensions are discussed.

Matters of the self-concept, "the cognitive representation of information pertaining to one's personal attributes" (Sedikides, 1995, p. 759), continue to generate innovative research endeavors and fuel controversy in psychology. Widely held theory and amassed empirical evidence indicate that models of self-conception would be incomplete without recognizing the multiple aspects of self-representations (Breckler, Pratkanis, \& McCann, 1991; Hart, Field, Garfinkle, \& Singer, 1997; Higgins, Van Hook, \& Dorfman, 1988; Sedikides \& Strube, 1997). Hoelter (1985a, 1985 b) has advanced a self-conception model that incorporates one's multiple identities as well as multiple dimensions along which these identities vary. He contends that "only by considering the spatial alignment of several identities in a meaning space can we begin to discover and examine key parameters of the self-conception system" (1985b, p. 1393), and has proposed and demonstrated sophisticated procedures for operationalizing and estimating aspects of this identity-dimension system.

This notion of multiple self-aspects is central to our recent investigations of self-congruence and personality. Hoelter's work, in particular, provides an apt theoretical and methodological precedent for the present article, wherein we propose measurement procedures intended to advance integrative understanding of two dominant self-conception areas: self-discrepancy theory and the five-factor model of personality. We begin by characterizing self-congruence research briefly, with an emphasis on self-discrepancy theory and conventional self-discrepancy measurement. Next, we consider the merits of a content-based measurement approach whereby personality traits serve as a semantic framework for assessing self-discrepancy. From these considerations follows our proposal 
to incorporate personality structure into the measurement of selfdiscrepancy. We detail this measurement strategy and present empirical support for its methodological robustness, operational flexibility, and construct validity.

\section{Self-Discrepancy Conceptualization and Measurement}

The idea of self-belief multiplicity has enjoyed extensive scientific attention. One might, for example, perceive oneself in different social roles-as a student, friend, or worker (Donahue, Robins, Roberts, \& John, 1993) — or as one or more possible selves (Markus \& Nurius, 1986). Furthermore, one's beliefs may concern multiple self-aspects (Linville, 1987) or facets (Hart et al., 1997). The general condition of consistency or compatibility amongst one's multiple self-beliefs can be characterized as self-congruence. It is, however, the antecedents and typically unfavorable consequences of self-belief incompatibility, or self-incongruence, that have occupied researchers.

With his exposition of a prominent self-incongruence theory, Higgins (1987) integrated several influential theories of self-conception and self-incongruence. Self-discrepancy theory (Higgins, 1987, 1996; Strauman, 1990; Strauman \& Higgins, 1988) concerns distinct emotional and motivational consequences associated with incongruence between particular self-beliefs. The theory assumes that an individual has multiple self-state representations, each of which constitutes one's cognitive representation of the traits or attributes that someone ${ }^{1}$ either (a) believes one actually possesses (i.e., actual self domain-one's self-concept), (b) would ideally like one to possess (i.e., ideal self domain-a selfguide), or (c) believes one should or ought to possess (i.e., ought self domain-another self-guide). Self-discrepancy theory posits explanations for the development of incongruities between certain self-state representations, or selves, and predicts that particular types of these self-discrepancies, of which actual-ideal (AI) and actual-ought (AO) discrepancy are the most basic, lead to distinct psychological outcomes.

1. Self-discrepancy theory also distinguishes among different standpoints on the self, or perspectives from which one's characteristics can be viewed (e.g., one's own, a significant other's). The present study concerns self-representations based on one's own standpoint only. 
For example, chronically accessible AI (vs. AO) is associated with a predisposition toward dejection- (vs. agitation-) related emotional vulnerability. In keeping with self-discrepancy theory, we adopt the selfstate representation as our working model of self-conception in this article.

Self-discrepancy theory's postulates have been tested extensively and generally supported in experimental, quasi-experimental, and observational settings. Investigators have examined its predictions in research on emotional distress (Boggiano \& Barrett, 1991), self-regulation (Roney \& Sorrentino, 1995), persuasion (Tykocinksi, Higgins, \& Chaiken, 1994), and such self-relevant constructs as empathy (Houston, 1990), loneliness (Kupersmidt, Buchele, Voegler, \& Sedikides, 1996), and happiness (Mikulincer \& Peer-Goldin, 1991). Others have used it as a framework for investigating the etiology of various disorders, both emotional (e.g., clinical depression [Scott \& O'Hara, 1993]) and psychophysiological (e.g., eating disorders [Forston \& Stanton, 1992] and drug addictions [Avants, Singer, \& Margolin, 1993]). Self-discrepancy theory has also been employed in research on reactions to stressful life events such as parenthood (Alexander \& Higgins, 1993) and unemployment (Sheeran \& McCarthy, 1992).

In their close methodological replication of a study reported by Higgins, Klein, and Strauman (1985), Tangney, Niedenthal, Covert, and Barlow (1998) failed to replicate several unique relations fundamental to self-discrepancy theory. These inconsistent results naturally raise questions about empirical support for self-discrepancy theory. Rather than harbor serious doubts about the theory's predictions, however, we concur with Tangney et al. that "it is tempting to suspect that part of the problem is the very method of self-discrepancy assessment advocated by Higgins (1987)" (p. 266). Given self-discrepancy theory's compelling, integrative appeal and the prolific accumulation of relevant research over more than a decade, the measurement of self-discrepancy has received disproportionately little attention.

Conventional self-discrepancy measurement: The Selves Questionnaire. Compared to self-conception operationalizations such as the systemic model advanced by Hoelter (1985a, 1985b), incongruities among selfstate representations are often measured rather broadly. Most selfdiscrepancy assessment has relied on the Selves Questionnaire (SQ; Higgins et al., 1985), a free-response instrument for which one lists 
attributes describing each self and then rates the extent to which the self possesses each attribute from 1 (slightly) to 4 (extremely). ${ }^{2}$ Following the conventional SQ scoring rubric (Higgins, Bond, Klein, \& Strauman, 1986, Study 2), a coder first eliminates synonyms - usually defined by Roget's Thesaurus - from the attributes listed for each self, thereby reducing within-self content redundancy. Each between-self attribute pair listed for two selves (up to $10 \times 10=100$ pairs) is then assigned a weight of $-1,0,1$, or 2 , according to its classification as a match (synonymous attributes whose extent ratings differ by less than two), nonmatch (neither synonymous nor antonymous), mismatch of extent (synonymous with extent ratings differing by two or more), or true mismatch (antonymous), respectively. Summing these weights over all attribute pairs yields an index of global self-discrepancy between the two selves.

With respect to Hoelter's (1985b) self-conception model, distinct self-state representations parallel the notion of distinct identities, and classifying SQ attribute pairs entails tacit semantic considerations. Explicit semantic dimensions, however, are notably absent from the conventional SQ approach. Self-discrepancy theory has been concerned more with the existence and magnitude of inconsistency between selfbeliefs than with belief content per se. Indeed, in eschewing the semantic restriction of preexisting items, the SQ's creators tailored it quite deliberately to the social-cognitive nature of self-state representations and self-discrepancies; its free-response format is intended to increase the likelihood that one lists personally important and accessible attributes. Nevertheless, the SQ assesses distance between discrepant selves in a global sense, without explicit reference to identifiable, meaningful dimensions. ${ }^{3}$ Elaborating the semantic space of self-discrepancy may enrich our understanding of relevant structures and processes. To this end, we now consider possibly suitable semantic dimensions.

2. Higgins, Shah, and Friedman (1997) have developed a computer-administered SQ similar in idiographic spirit to the original instrument. Its instructions and response format differ notably, and it includes an independent assessment of self-guide strength based on response latency. Convergence between the original and computerized SQs remains to be examined.

3. Other operationalizations of self-discrepancy have included an interview version of the SQ (Strauman, 1992), Mikulincer and Peer-Goldin's (1991) grid test, a semantic differential derived from Big-Five personality traits and scored using Osgood's distance formula (Sánchez-Bernardos \& Sanz, 1992), and a particularly promising semantic space model proposed by Hart et al. (1997). Some of these operationalizations do incorporate explicit semantic dimensions. However, they are less prevalent than the SQ. 


\section{The Five-Factor Model of Personality as a Semantic Framework}

What semantic dimensions underlie self-beliefs and self-discrepancies? This question has not been addressed, to our knowledge, which is consistent with Hoelter's (1985b) observation that rules for specifying self-conception dimensions are not well established. One reasonable criterion is that dimensions should relate to self-beliefs via one's theoretical interests. Hence, different investigators may favor different dimensions. Hoelter's model includes eight dimensions, of which affect-depression, anxiety, and identity salience seem particularly pertinent to self-discrepancy. Another alternative is some type of personality description, which should capture a substantial portion of self-belief content. For both theoretical and practical reasons, we opted to define dimensions using personality traits.

Trait personologists have documented countless efforts to identify and classify enduring dispositional characteristics. Despite considerable controversy accompanying its development and promulgation, the five-factor model of personality (FFM) boasts growing consensus. The FFM factor structure comprises five dimensions commonly interpreted (in the BigFive tradition) as Surgency or Extraversion; Agreeableness or Kindness; Conscientiousness; Emotional Stability or reversed Neuroticism; and Intellect, Openness, or Culture. These broad traits have been found to underlie personality description consistently across participant and variable samples, factor extraction and rotation methods, self-report versus others' ratings, and other methodological variations. Goldberg (1990), McCrae and John (1992), and Saucier (1997) have reviewed FFM research extensively.

The FFM is not accepted unanimously (McAdams, 1992), particularly for the scientific study of genotypic personality structure (Block, 1995a, 1995b). Not all proposed personality-structure models are factor analytic (Block, 1971; Hofstee, de Raad, \& Goldberg, 1992), not all factor models comprise five factors, and not all five-factor solutions are identical conceptually. McAdams (1995) considers dispositional traits-“those relatively nonconditional, relatively decontextualized, generally linear, and implicitly comparative dimensions of personality" (p. 371)-the least informative level of person description. Nevertheless, insofar as issues central to self-discrepancy theory concern traits or attributes constituting laypersons' self-beliefs, the very properties that limit their 
relevance to genotypic personality in fact recommend FFM traits for organizing and comparing laypersons' phenotypic self-belief content. Its relative parsimony and widespread familiarity further endorse the FFM's candidacy for self-discrepancy measurement.

\section{Proposed Measurement Strategy}

Having settled on reasonable self-conception and semantic models, we now consider an alternative method of self-discrepancy assessment that extends existing practice toward Hoelter's (1985b) approach. The general strategy entails coding self-belief content against explicit semantic dimensions to facilitate content comparisons among selves. To illustrate specifically how self-discrepancies can be operationalized using FFM personality dimensions, and how the incorporation of FFM content influences self-discrepancy findings, we first describe and justify procedures for collecting and coding FFM content from individuals' self-state representations. We then demonstrate the flexibility of these data for addressing issues pertinent to both self-discrepancy and phenotypic personality structure, and present preliminary construct validity evidence using criterion variables germane to the FFM and to self-discrepancies.

\section{METHOD}

\section{Practical Measurement Considerations}

The problem of locating objects and dimensions in a common space typically involves relations between objects and dimensions (e.g., where selves fall along FFM factors), relations among objects (e.g., semantic distances between selves), and relations among dimensions (e.g., intercorrelations between FFM factors). Data or assumptions about any two types of these relations often provide information about the third type. Besides Hoelter's (1985b) factor analysis procedures, established methodologies adaptable to this general measurement problem include multidimensional scaling (Young \& Hamer, 1987), cluster analysis (Anderberg, 1973), and Q-sort procedures (Block, 1961/1978). Our present approach was tailored to self-discrepancy research and entailed (a) eliciting several attributes that constitute each of a respondent's different self-beliefs, (b) using information about these attributes to locate each self along each FFM dimension, then (c) using these locations to assess discrepancy among selves. Below we address practical matters relevant to the first two of these steps; the third we discuss in a later section. 
Collecting self-beliefs. To collect information about respondents' self-beliefs, we administered the conventional $S Q$, which yields free-response self-descriptive attributes for each self. Viable alternative instruments include established FFM measures (e.g., Big Five Inventory [John, Donahue, \& Kentle, 1991], NEO Personality Inventory [Costa, McCrae, \& Dye, 1991]) or Q-sorts based on the FFM (Flora, Panter, \& Hafdahl, 1998). The primary advantage of the SQ is that attributes listed in free-response self-descriptions are more likely important and accessible to the respondent than items in preexisting pools (Higgins et al., 1985). Also, because the same unstructured attributes could yield diverse types of content, this free-response method lends itself to other semantic-dimension choices. Finally, administering the $S Q$ as it has been for the past decade promotes continuity with and secondary analysis of previous self-discrepancy research and data.

Coding self-belief content against the FFM. Had we collected self-beliefs using an established FFM instrument, the personality subscale scores (e.g., Extraversion, Agreeableness) for each self would locate it along subscale dimensions. With free-response attributes, however, locating each self along FFM dimensions requires further information relating attributes to dimensions. One solution is first to approximate each attribute's location on the FFM dimensions using an external semantic standard, then to aggregate these locations across attributes. An obvious (though not the only) source for these location estimates would be a FFM factor analysis of self-descriptive attributes, preferably one whose item pool covers most SQ responses.

To the extent that the FFM represents universal dispositions (McCrae \& Costa, 1997), the numerous factor-analytic solutions to the personality-structure problem could be used interchangeably. Factor solutions based on different sampling schemes for participants and lexical terms, however, have varied in the nature and number of items defining each factor (Saucier, 1997). Our choice of a specific factor analysis was governed by the prominence of a particular study among the FFM literature and by the availability of adequate results. Goldberg (1990) reported a factor analysis wherein 187 college students rated the self-descriptiveness of 1,710 trait adjectives assembled following the lexical tradition (see Goldberg, 1982, for details). The first five orthogonal factors were interpreted as Surgency/Extraversion, Agreeableness, Conscientiousness, Emotional Stability, and High Intellect/Imagination. ${ }^{4}$ We also coded the SQ against

4. The factor-analytic results that L. R. Goldberg generously provided for the present study are not factor loadings per se, but "are the correlations (the same as factor loadings) of each of the 1,710 terms with the Big-Five factors, with the factors defined by orthogonal factor scores derived from [Goldberg's (1992)] 100 unipolar Big-Five factor markers. . . A Actually, only 99 of [the] 100 unipolar markers are included in the 1710 [sic], so that is the set of terms that was factored. ...” The 99 markers were factor-analyzed using principal-components extraction and varimax rotation (L. R. Goldberg, personal communication, May 23, 1997). These correlations were treated essentially as factor loadings. 
Saucier's (1997) results to address potential artifacts arising from idiosyncrasies of Goldberg's study. ${ }^{5}$

To assess the construct validity of these procedures, we examined associations involving self-belief FFM scores, some of the many possible personality-based self-discrepancy (PBSD) indices constructed from these scores, and criterion indicators of constructs pertinent to personality and self-discrepancy. Specifically, we correlated FFM scores for the actual self with an established FFM measure, and correlated various PBSD scores with two depression indices, a measure of social self-esteem, and conventional SQ self-discrepancies.

\section{Participants}

A total of 199 undergraduate students participated in a study of self and perceived mental health for partial course credit (Gramzow, Sedikides, Panter, \& Insko, in press); eight participants' data were omitted, ${ }^{6}$ leaving 130 females $(68.1 \%)$ and 61 males $(31.9 \%)$. Based on self-reported demographic information, $84.8 \%$ of these 191 respondents were White, not of Hispanic origin; 9.4\%, Black (African American), not of Hispanic origin; 3.7\%, Asian or Pacific Islander; and $2.1 \%$, of other ethnicity. Most respondents $(40.3 \%)$ were first-year college students, followed by sophomores (33.0\%), juniors (19.9\%), seniors $(6.3 \%)$, and special students $(0.5 \%)$. Their ages ranged from 17 to 55 years $(M d n$ $=19.00 ; M=19.74, S D=3.60)$. All 191 participants completed the SQ; 181 completed all measures reported herein.

\section{Instruments}

Selves Questionnaire. The SQ (Higgins et al., 1986, Study 2) asks respondents to list up to 10 self-descriptive attributes for each of the actual, ideal, and ought domains - in that order-from their own standpoint, then rate from 1 (slightly) to 4 (extremely) the extent to which they believe they actually possess, would ideally like to possess, or ought to possess each attribute. SQs were coded by

5. Saucier (1997) reported a study in which 700 community members rated the selfdescriptiveness of 500 familiar person-descriptive adjectives. Results included three-, five- and seven-factor solutions. G. Saucier generously made results from the latter solution available for the present research. The seven factors were interpreted as Extraversion, Kindness/Agreeableness, Conscientiousness, Emotional Stability, Intellect, Appeal, and Invective. Although Goldberg's (1990) and Saucier's participant and variable samples differed notably, the conceptual similarity of both solutions' first five factors permitted comparison of findings between the two FFM-based coding schemes.

6. Two respondents did not complete the SQ, three did not follow SQ instructions, and three contributed no responses for at least one self domain. 
the FFM-based strategy described below as well as the conventional approach described above.

Big-Five Inventory, Version 44. The BFI-44 (John et al., 1991) is a self-report instrument designed to assess broad personality traits within the FFM framework. Respondents rate, from 1 (disagree strongly) to 5 (agree strongly), each of 44 self-descriptive phrases that complete an I consider myself someone who ... stem. Extraversion, Agreeableness, Conscientiousness, Neuroticism, and Openness subscale scores are computed from ratings averaged across appropriate items. A higher subscale score indicates that the factor is more characteristic of the respondent.

Beck Depression Inventory. The BDI (Beck, Ward, Mendelson, Mock, \& Erbaugh, 1961) is a self-report instrument designed to assess one's current level of clinical depression. Respondents endorse one of four to six alternative descriptors in each of 21 sets of statements. Each alternative is weighted by its degree of depressive involvement. Weights are summed for a total depression score. Higher scores represent greater clinical depression. The BDI has shown adequate reliability and validity in college populations (Beck, Steer, \& Garbin, 1988). Strauman and Higgins (1988) have noted that the BDI does not discriminate between dejection- and agitation-related depression.

Center for Epidemiological Studies Depression Scale. The CES-D (Radloff, 1977), another self-report depression instrument, emphasizes affective symptomatology and is intended for use in the general population. Respondents rate each of 20 items regarding their feelings or behavior during the past week. Ratings are weighted from 0 (rarely or none of the time) to 3 (most or all of the time) and summed for a total score. Higher scores indicate greater depressive symptomatology. Radloff reported adequate reliability and validity across a variety of sub-populations.

Texas Social Behavior Inventory, Form A. The TSBI was constructed to tap self-esteem or social competence; Form A of is one of two parallel short forms (Helmreich \& Stapp, 1974). Respondents rate the self-descriptiveness of 16 items, which are then weighted from 0 (not at all characteristic of me) to 4 (very much characteristic of me) and summed for a total self-esteem score. Unlike global self-esteem instruments, the TSBI assesses social self-esteem specifically.

\section{Procedure}

At each of five weekly small-group sessions, participants completed several counterbalanced measures of perceived mental health and self-concept regulation and structure, including the SQ, BFI-44, BDI, CES-D, and TSBI. In addition 
to scoring these five instruments by conventional protocols, we coded SQ responses against the FFM.

Constructing FFM personality scores. We constructed five FFM "personality scores" for each respondent's three selves. As with typical personality instruments, each score is an average weight across items. Here, items are the respondent's self-belief attributes, and each attribute's five weights are loadings from Goldberg's (1990) factor-analysis. As described and illustrated in the Appendix, each Goldberg-based mean factor loading (MFL), or personality score, was computed as the mean (across a person's attributes for a domain) of loadings on the corresponding factor. Averaging, versus summing, adjusts for "differential generativity" among selves. ${ }^{7}$ Fifteen MFLs were thus constructed for each respondent: one on each FFM dimension (Surgency, Agreeableness, Conscientiousness, Emotional Stability, and Intellect) for each self domain (actual, ideal, and ought). Using the same method, we coded SQ attributes against loadings on the first five factors from Saucier's (1997) seven-factor solution. In a later section we show that MFLs are relatively robust to using raw factor loadings versus alternative weights.

MFLs can be interpreted much like scores from typical personality instruments. For each SQ attribute a respondent lists to describe a particular self (e.g., actual), we assume the respondent perceives that self as located near that attribute's (numerically) positive semantic pole. In turn, each of the attribute's five factor loadings quantifies an attribute-factor association and therefore reflects the self's approximate location along that factor (based solely on that attribute). ${ }^{8}$ As an average location across attributes, an MFL reflects a self's location along an FFM dimension and, hence, that dimension's degree of selfdescriptiveness: The more positive (negative) a self's MFL on a dimension, the

7. Repeated-measures planned orthogonal comparisons showed that SQ respondents listed significantly more attributes for the actual $(M=9.41, S D=1.19)$ than for the combined ideal $(M=8.17, S D=2.32)$ and ought $(M=7.87, S D=2.41)$ self domains, $F(1,190)=106.10, p<.001$, and significantly more attributes for the ideal than for the ought domain, $F(1,190)=7.73, p=.006$. Consequently, actual MFLs were computed from more attributes on average than were ideal and ought MFLs, and likewise for ideal versus ought. Because all respondents completed the actual, ideal, and ought selfdescriptions in that order, the source and implications of this "differential generativity" were difficult to identify. Houston (1990) found no difference in conventional AI or AO scores among groups that responded to the three domains in either of the six possible sequences, which begins to address this problem.

8. The trait content of each attribute is defined normatively, with respect to Goldberg's (1990) participants. Thus, attribute-factor association refers to an attribute's tendency to covary with the latent factor across persons, holding other modes or variables constant. As in most $R$ technique factor analyses (Gorsuch, 1983, esp. Chapter 15), these associations describe a person's unique semantic representation of attributes and factors inasmuch as he or she typifies Goldberg's sample. 
further that self's location toward that dimension's positive (negative) pole, and the more self-descriptive that pole. Note that positive or negative selfdescriptiveness does not imply desirability or importance. Finally, MFLs on a single dimension can be compared meaningfully, but MFLs should be compared between different dimensions only after ensuring that the scales' properties support such comparisons. ${ }^{9}$

Constructing personality-based self-discrepancy scores. Three types of personality-based AI and AO self-discrepancies were constructed from MFLs:

1. Each of 10 dimension-specific self-discrepancies was computed as the signed MFL difference between the two constituent domains on that FFM dimension (e.g., ideal Surgency minus actual Surgency).

2. Each of two average self-discrepancies was computed as the arithmetic mean of the five dimension-specific self-discrepancies.

3. Each of two multidimensional self-discrepancies was computed as the five-dimensional Euclidean distance between the two domains using the general Pythagorean theorem. For instance, multidimensional AI is the square root of the summed (across all five dimensions) squared differences between each actual-ideal MFL pair.

Taking the absolute value of dimension-specific and average PBSDs would increase their similarity to conventional SQ self-discrepancies, which quantify the magnitude but not the direction of self-belief mismatch. Note that numerous alternatives exist for computing average (median, geometric or harmonic mean; any of these applied to absolute dimension-specific PBSDs) and multidimensional (various Minkowski power metrics, the Cannberra metric, angular separation; see Cox \& Cox, 1994) PBSDs.

9. Due to mathematical constraints (e.g., on variable, factor, and loading distributions) and sampling considerations (e.g., of variables and participants), the numerical values of factor loadings are directly interpretable only with reference to variables and participants like those in the factor-analytic study. The 874 unique SQ responses used to compute MFLs (see Appendix) comprised a subset of Goldberg's (1990) adjective pool and several responses not in that pool. Also, whereas Goldberg's participants each rated every adjective, the frequency of usage varied widely across SQ attributes. Hence, any functional numeric relation between factor analysis results and MFLs is difficult to specify. MFL numerical values are of little relevance for this paper, however, and where MFL properties are assumed for statistical procedures, we justify them empirically. 


\section{Statistical Analytic Aims and Procedures}

Our primary hypothesis-testing aims were to determine whether PBSDs obtain empirically and, most important, whether the pattern of discrepancy among self domains varies among FFM dimensions. A secondary aim was to demonstrate the versatility of self-discrepancy and personality-structure operationalizations within a system of selves and semantic dimensions. Statistical procedures for analyzing MFL mean differences were used to examine the empirical nature of self-discrepancies when either (a) MFLs are combined across FFM dimensions, (b) discrepancies are compared among dimensions, or (c) discrepancy is assessed within specific dimensions (corresponding to main, interaction, and simple effects in analysis of variance [ANOVA], respectively). Similar analyses addressed the nature of personality structure when either (a) MFLs are aggregated across self domains, (b) personality structure is compared among domains, or (c) personality structure is assessed within specific domains.

\section{RESULTS}

MFL means and standard deviations appear in Table $1 .{ }^{10}$ Most of the 15 MFLs and the 105 MFL pairs exhibited satisfactory univariate and bivariate normality, respectively, and the MFLs' relatively homogeneous standard deviations satisfied dispersion assumptions for later inferential procedures. ${ }^{11}$ The pattern of mean MFLs across the five FFM dimensions for a particular self domain is that self's personality profile. Figure 1 depicts the 15 MFL means as a profile plot for each self domain.

\section{Descriptive Profile Features}

The MFL profiles in Figure 1 reflect notable patterns of self-discrepancy across, among, and within FFM dimensions. Viewed alternatively, the personality profiles represent phenotypic personality structure across, among, and within self domains. Here we highlight descriptive patterns from both perspectives.

10. Correlation and variance-covariance matrices for these and other versions of Goldberg- and Saucier-based scores are available from the first author.

11. Multivariate normality was required for all primary and follow-up inferential procedures. Because all procedures entailed multiple dependent measurements across domains treated multivariately, only profile analyses required the additional dispersion assumption of scale commensurability. 


\section{Table 1}

Goldberg-Based Mean Factor Loading Means and Standard Deviations for Each Self Domain on Each Personality Dimension

\begin{tabular}{|c|c|c|c|}
\hline \multirow{2}{*}{$\begin{array}{l}\text { FFM } \\
\text { personality } \\
\text { dimension }\end{array}$} & \multicolumn{3}{|c|}{ Self domain } \\
\hline & Actual & Ideal & Ought \\
\hline Surgency & $.055(.081)$ & $\mathbf{. 1 1 6}(.081)$ & $.072(.069)$ \\
\hline Agreeableness & $.153(.093)$ & $.183(.083)$ & $.243(.083)$ \\
\hline Conscientiousness & $.077(.078)$ & $.101(.063)$ & $\mathbf{. 1 3 1}(.071)$ \\
\hline Emotional Stability & $-.007(.082)$ & $.106(.063)$ & $.084(.070)$ \\
\hline Intellect & $.055(.050)$ & $.078(.061)$ & $.048(.055)$ \\
\hline
\end{tabular}

Note. $N=191$. Tabled values are Goldberg-based mean factor loading (MFL) means (standard deviations in parentheses). Boldface denotes domain with highest mean on that dimension.

Self-discrepancy. First, mean MFLs appear discrepant (i.e., they differ or vary) among at least two and usually all three domains on every dimension, particularly so on Agreeableness and Emotional Stability and least so on Intellect. One could imagine averaging the five MFLs for each domain across dimensions into a single "composite" personality score. This composite for the actual self would fall clearly below that for both self-guides; self-guide composites, however, would be difficult to distinguish. Second, self-discrepancy patterns clearly differ among personality dimensions. Even where selves are ordered similarly along two dimensions (e.g., on both Surgency and Emotional Stability, AI is the largest discrepancy; on both Agreeableness and Conscientiousness, AO is dominant), particular discrepancy magnitudes differ (e.g., AO is negligible on Surgency but substantial on Emotional Stability). Finally, this variability of self-discrepancy patterns among FFM dimensions suggests that the unique discrepancies within each dimension yield a more articulated description of self-belief incompatibility than do discrepancies based on a composite dimension.

Personality structure. Averaging MFLs across the three selves would yield an "aggregate" MFL on each dimension. Clearly, the aggregate would be highest on Agreeableness, suggesting that Agreeableness is the most positively self-descriptive among FFM dimensions. This aggregation, however, obscures profile differences among selves. Although Agreeableness is highest for all domains, its dominance is most prominent for the ought self; the actual self is unique in its relatively low 


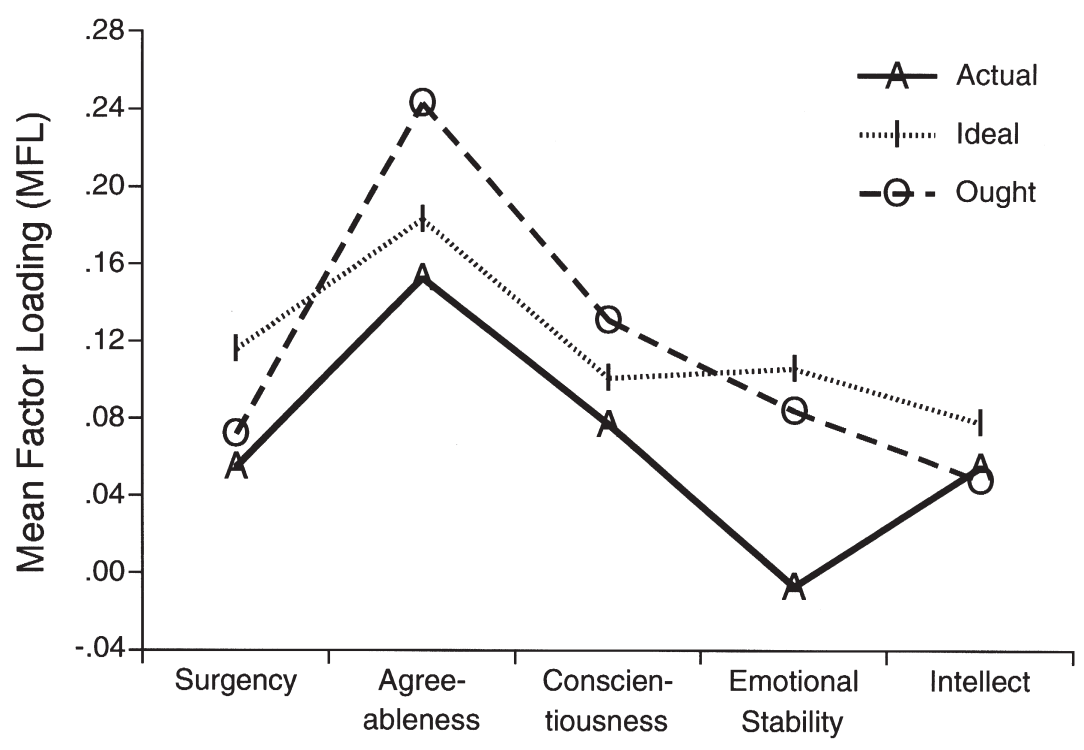

FFM Personality Dimension

\section{Figure 1}

$N=191$. Profile plot of mean Goldberg-based mean factor loading (MFL) for each self domain across personality dimensions.

Emotional Stability; and descriptiveness for the ideal self is relatively homogeneous across dimensions. Incidentally, variation in profile shape among domains is a type of self-discrepancy, in that it reflects different alignments of self-beliefs in semantic space. These descriptive observations are substantiated below with inferential procedures.

\section{Multivariate and Univariate Self-Discrepancy Analyses}

The 15 MFLs were treated as five personality variables measured under three within-subjects conditions: instructions to describe one's actual, ideal, and ought selves. Various operationalizations of FFM-based self-discrepancy were examined with procedures related to this doubly multivariate repeatedmeasures ANOVA design (Stevens, 1996). Besides the omnibus multivariate 
analysis of variance (MANOVA) (i.e., comparing all domains on all dimensions), follow-up procedures included multivariate and univariate (i.e., dimension-specific) self-domain contrasts and univariate analyses of variance (ANOVAs). Self-domain contrasts were used to operationalize and test four meaningful self-discrepancies: actual versus ideal, representing actual-ideal discrepancy (AI); actual versus ought, representing actual-ought discrepancy (AO); actual versus averaged ideal and ought, representing discrepancy between the self-concept and an aggregate self-guide (A[IO]); and ideal versus ought, representing self-guide discrepancy (IO).

Effect sizes for these analyses, as indexed by the multivariate correlation ratio, 1 - Wilks' $\Lambda$ (Tatsuoka, 1988), are summarized in Table $2 .{ }^{12}$ For analyses comparing MFLs among selves, a larger effect size represents greater discrepancy among the constituent self-beliefs. The omnibus MANOVA yielded a (statistically) significant multivariate difference, Wilks' $\Lambda=.27, F(10,181)=48.79, p<.001$. This large effect $(1-.27=$ .73) demonstrates substantial discrepancy among the actual, ideal, and ought selves on the collective five FFM dimensions. All follow-up multivariate self-domain contrasts-AI, AO, A[IO], and IO-were significantly non-zero, all $p$ s $<.001$. That is, the selves in four specific combinations are discrepant multivariately.

By comparing mean MFLs among self domains on each personality dimension, univariate ANOVAs examined each dimension's contribution to the above multivariate discrepancy. All five univariate tests were significant, all $p \mathrm{~s}<.001$, which demonstrates self-discrepancy on all dimensions. ${ }^{13}$ Dimension-specific self-discrepancy patterns were analyzed further by testing self-domain contrasts on each dimension. Of the 20 contrasts-whose estimates can be computed directly from means in Table 1 -only 2 (Intellect AO and A[IO]) were statistically indiscernible

12. The large sample size and the repeated-measures nature of all analyses yielded considerable statistical power for all significance tests. Bearing in mind that trivial effects are detectable with adequate power, one should interpret $p$ values cautiously. Therefore, tabled values are $1-$ Wilks' $\Lambda$, a multivariate strength-of-association or effect-size index analogous to $R^{2}$ or $\eta^{2}$. This index is bounded by zero and unity, simplifies to $R^{2}$ or $\eta^{2}$ in the univariate case, and can be interpreted as the proportion of variation in the system explained by the model.

13. The multivariate model for repeated-measures ANOVA used here does not assume sphericity (Johnson \& Wichern, 1992; Maxwell \& Delaney, 1990; Stevens, 1996). 
Table 2

Self-Discrepancy Analyses: Effect-Size Summary for Multivariate, Univariate, and Profile Analysis Omnibus Tests and Self-Domain Contrasts

\begin{tabular}{lccccc}
\hline $\begin{array}{l}\text { Analysis/ } \\
\text { FFM personality }\end{array}$ & & \multicolumn{4}{c}{ Self-domain contrast $^{\mathrm{b}}$} \\
\cline { 3 - 6 } dimension & Omnibus $^{\mathrm{a}}$ & $\mathrm{AI}$ & $\mathrm{AO}$ & $\mathrm{A}[\mathrm{IO}]$ & $\mathrm{IO}$ \\
\hline Multivariate & $\mathbf{7 3}$ & $\mathbf{6 3}$ & $\mathbf{6 3}$ & $\mathbf{6 2}$ & $\mathbf{4 7}$ \\
Univariate & & & & & \\
$\quad$ Surgency & $\mathbf{2 4}$ & $\mathbf{1 9}$ & 02 & $\mathbf{1 1}$ & $\mathbf{2 1}$ \\
Agreeableness & $\mathbf{4 1}$ & 06 & $\mathbf{3 6}$ & $\mathbf{2 3}$ & $\mathbf{2 9}$ \\
Conscientiousness & $\mathbf{2 5}$ & 05 & $\mathbf{2 3}$ & $\mathbf{1 5}$ & $\mathbf{1 3}$ \\
Emotional Stability & $\mathbf{5 2}$ & $\mathbf{5 2}$ & $\mathbf{4 2}$ & $\mathbf{5 0}$ & $\mathbf{0 8}$ \\
Intellect & $\mathbf{1 7}$ & $\mathbf{1 0}$ & 01 & 02 & $\mathbf{1 6}$ \\
Profile analysis & & & & & \\
$\quad$ Parallelism & $\mathbf{6 0}$ & $\mathbf{3 5}$ & $\mathbf{4 3}$ & $\mathbf{3 7}$ & $\mathbf{4 7}$ \\
Level coincidence & $\mathbf{5 7}$ & $\mathbf{5 5}$ & $\mathbf{5 4}$ & $\mathbf{5 7}$ & 00 \\
\hline
\end{tabular}

Note. Tabled values are $1-$ Wilks' $\Lambda$, an effect-size index analogous to $R^{2}$, with decimals omitted. Self-domain contrasts: $\mathrm{AI}=$ actual vs. ideal, $\mathrm{AO}=$ actual vs. ought, $\mathrm{A}[\mathrm{IO}]=$ actual vs. aggregated ideal and ought, $\mathrm{IO}=$ ideal vs. ought.

${ }^{\mathrm{a} O m n i b u s}$ test of multivariate mean difference $(d f=10,181)$, univariate mean difference $(d f=2,189)$, parallelism $(d f=8,183)$, and level coincidence $(d f=2,189) .{ }^{\text {b }}$ Self-domain contrasts for multivariate mean difference $(d f=5,186)$, univariate mean difference $(d f$ $=1,190)$, parallelism $(d f=4,187)$, and level coincidence $(d f=1,190)$.

Two-tailed $p$ values: Italic indicates $p<.05$; boldface, $p<.001$.

from zero; 15 were statistically significant at $p<.001$; and 5 yielded effect sizes beyond .25 (see Table 2).

\section{Personality-Profile Analyses}

The 15 MFLs also were treated as commensurable measures ${ }^{14}$ in a repeated-measures profile analysis. Profile analysis is often used to identify differences among two or more groups' patterns of mean scores

14. Due to complex relations among factor analysis constraints, the sampling of attributes into SQ responses and adjectives into Goldberg's (1990) pool, and the procedure used to construct MFLs, MFL commensurability (in the usual sense of scale variability) is not established readily on statistical-theoretical grounds. The MFLs' relatively homogeneous dispersions, however, justify commensurability empirically. 
(i.e., profiles) on an instrument battery (Johnson \& Wichern, 1992; Stevens, 1996). Three omnibus procedures-which resemble tests of the interaction and main effects in two-way factorial ANOVA-were used to test hypotheses about specific personality-profile features. The omnibus test of profile parallelism addressed whether self-discrepancies vary among personality dimensions; level coincidence, whether composite (across dimensions) MFLs vary among selves; and flatness, whether aggregate (across selves) MFLs vary among dimensions. In addition, follow-up profile analyses tested focused self-discrepancy and personalitystructure hypotheses.

Parallelism. The omnibus parallelism hypothesis was rejected, Wilks' $\Lambda=.40, F(8,183)=33.80, p<.001$, demonstrating that the pattern of discrepancy among selves varies among personality dimensions. An equivalent interpretation is that personality structure is discrepant among selves. Parallelism also was untenable for all specific self-domain contrasts (AI, AO, $\mathrm{A}[\mathrm{IO}]$, and $\mathrm{IO}$ ), all $p \mathrm{~s}<.001$. Table 2 includes an effect-size summary for these parallelism analyses and for the following level-coincidence procedures.

Level coincidence. The omnibus test of level coincidence was statistically significant, Wilks' $\Lambda=.43, F(2,189)=124.90, p<.001$, which suggests that the composite (i.e., averaged across personality dimensions) personality score varies among selves. Follow-up self-domain contrasts showed that level coincidence was untenable for all comparisons with the actual self. Specifically, the composite MFL mean for actual was significantly lower than that for ideal, for ought, and for aggregated ideal and ought, $F(1,190)=233.30,226.11$, and 250.98, respectively, all $p$ s <.001. Level coincidence was not rejected, however, for IO, $F(1,190)$ $=0.65, p=.421$, suggesting that the ideal and ought composite MFLs are coincident. That is, the typical FFM content of the two self-guides is indistinguishable when collapsed across personality dimensions.

Flatness. The omnibus profile flatness test was significant, Wilks' $\Lambda=$ $.22, \mathrm{~F}(4,187)=165.76, p<.001$, which suggests that the aggregate (i.e., averaged across self domains) MFL varies among the five personality dimensions. One set of follow-up analyses showed that flatness was also untenable for each of the actual, ideal, and ought selves, all $p s<.001$. In addition, contrasts were tested to compare the mean MFL on each 
personality dimension with the mean MFL averaged across the other dimensions (for an aggregate self domain as well as for each domain separately). Again, contrast estimates can be computed directly from means in Table 1. Whether aggregated across domains or examined separately for any self domain, Agreeableness yielded the largest positive effect among dimensions. That is, Agreeableness was most positively self-descriptive among the five dimensions, regardless of domain. The largest negative effect (i.e., the lowest positive self-descriptiveness) occurred on Intellect for the aggregate domain and for ideal and ought separately, and on Emotional Stability for actual. Table 3 includes effect sizes summarizing these flatness analyses.

\section{Sensitivity Analyses}

Goldberg-versus Saucier-based results. All analyses above were conducted for Saucier-based MFLs as well, and we assessed the correspondence between Goldberg- and Saucier-based results. One procedure entailed examining Pearson correlations between convergent, monotrait MFL pairs (e.g., Goldberg-based actual Surgency and Saucier-based actual Extraversion) and between divergent, heterotrait (i.e., off-diagonal) pairs. Self-discrepancy and personality-structure patterns were also compared between versions by informal inspection. Finally, we compared inferential effect sizes and $p$ values.

Although monotrait MFL correlations were rather weak for a few domain-dimension combinations, and some heterotrait correlations were rather strong, all 15 monotrait correlations were stronger than all 210 heterotrait correlations. Furthermore, the mean correlation for monotrait pairs $(\bar{r}=.80, S D=.08)$ was substantially stronger than the mean absolute correlation for heterotrait pairs $(|\vec{r}|=.12, S D=.11)$. Self-discrepancy patterns replicated quite well between the two versions, particularly in terms of self-domain ordering along each personality dimension. Moreover, the magnitude of separation among domains was relatively similar between versions, with some exceptions on Conscientiousness and Intellect. Personality structure, in terms of specific profile shape, was less consistent between versions.

As for inferential results, effect sizes for both the doubly multivariate MANOVA and the profile analysis, with some exceptions on Conscientiousness and Intellect, were similar for procedures that addressed self-discrepancy issues (viz., omnibus MANOVA, parallelism, 


\section{Table 3}

Personality-Structure Analyses: Effect-Size Summary for Omnibus Flatness Tests and Personality-Dimension Contrasts Across and Within Self Domains

\begin{tabular}{lcccc}
\hline Reference & & \multicolumn{3}{c}{ Self domain } \\
\cline { 3 - 5 } $\begin{array}{l}\text { personality } \\
\text { dimension }^{\mathrm{a}}\end{array}$ & Aggregate $^{\mathrm{b}}$ & Actual & Ideal & Ought \\
\hline Omnibus $^{\mathrm{c}}$ & $\mathbf{7 8}$ & $\mathbf{6 8}$ & $\mathbf{4 6}$ & $\mathbf{7 9}$ \\
Univariate & & & & \\
Surgency & $\mathbf{1 8}$ & -03 & -00 & $\mathbf{- 3 4}$ \\
Agreeableness & $\mathbf{+ 7 5}$ & $\mathbf{+ 5 8}$ & $\mathbf{+ 4 1}$ & $\mathbf{+ 7 0}$ \\
Conscientiousness & +01 & +02 & -06 & +04 \\
Emotional Stability & $\mathbf{- 4 7}$ & $\mathbf{5 5}$ & -03 & $\mathbf{- 1 7}$ \\
Intellect & $\mathbf{- 5 0}$ & -03 & $\mathbf{- 3 0}$ & $\mathbf{- 6 4}$ \\
\hline
\end{tabular}

Note. $N=191$. Tabled values are $1-$ Wilks' $\Lambda$, an effect-size index analogous to $R^{2}$, with decimals omitted; sign indicates direction of contrast: $+=$ dimension is more positively self-descriptive than average, $-=$ dimension is less positively self-descriptive than average.

aPersonality dimension contrasted with the averaged remaining four dimensions $(d f=1$, 190). ${ }^{\mathrm{b}}$ Averaged across self domains. ${ }^{\mathrm{c} O m n i b u s}$ test of profile flatness $(d f=4,187)$.

Two-tailed $p$ values: Italic indicates $p<.05$; boldface, $p<.001$.

and level-coincidence tests; univariate ANOVAs; and multivariate, parallelism, and level-coincidence self-domain contrasts). Even univariate self-domain contrasts were fairly concordant between versions. Inferential results addressing personality structure (profile flatness procedures, primarily) were less robust: Omnibus flatness tests yielded similar results, but specific personality patterns differed.

Alternative weighting schemes for MFLs. Anticipating concerns about the reliability and stability of raw (including near-zero) factor loadings, we examined two weighting alternatives. ${ }^{15}$ First, using Cohen and Cohen's (1983, p. 61) guidelines for small, medium, and large correlations, we assigned weights of $0,1,2$, and 3 , respectively, to loadings below .10 , between .10 and .30 , between .30 and .50 , and above .50 in absolute value (e.g., .09 became $0 ;-.45$ became -2 ). MFLs computed from these discretized loadings correlated almost perfectly with raw

15. We thank Eileen M. Donahue for encouraging us to examine alternative strategies. 
MFLs: The 15 monotrait correlations ranged from .94 to .98 ( $\bar{r}=.96, S D$ $=.01)$; the 210 heterotrait correlations were substantially smaller $(|\vec{r}|=$ $.11, S D=.10)$. As a second strategy, we constrained to zero all "nonsalient" loadings (those below .30 in absolute value), a more severe approach given that such arbitrary cut-offs may reflect standard errors poorly (Cudeck \& O'Dell, 1994). Even this substantial loss of information (86\% of all loadings were eliminated) yielded high positive monotrait correlations $(\bar{r}=.81, S D=.08)$ and near-zero heterotrait correlations $(|\vec{r}|=.10, S D=.09)$.

\section{Construct Validity of Mean Factor Loadings and Personality-Based Self-Discrepancies}

To assess MFL and PBSD construct validity, we first examined Pearson correlations between actual-self MFLs and BFI-44 subscale scores. The five monotrait correlations were the highest in the matrix (see Table 4). Although these moderately positive correlations were too low to claim strong MFL-BFI-44 convergence, MFLs appear to measure constructs akin to FFM personality content. Next, we examined the correlation between each of 16 self-discrepancy indices (dimension-specific, average, and multidimensional PBSDs, as well as conventional SQ global discrepancies; both AI and AO) and BDI and CES-D depression, TSBI self-esteem, and conventional global SQ discrepancies (SQ-AI and SQ$\mathrm{AO}$ ). Table 5 displays these self-discrepancy-outcome correlations.

Depressive emotional discomfort. Although most PBSDs were uncorrelated with BDI and CES-D depression, both depression measures yielded weak positive associations with Surgency, Emotional Stability, and average AI and AO PBSDs. SQ-AI and SQ-AO also correlated only weakly with depression, except for the moderate correlation between the BDI and SQ-AI, $r(179)=.30, p_{\text {Bon }}<.05$. Depression correlated slightly more strongly with AI than with $\mathrm{AO}$ indices.

Social self-esteem. TSBI social self-esteem correlated weakly negatively with Emotional Stability and multidimensional AI and AO, and moderately negatively with Surgency and average AI and AO. Both SQ discrepancies correlated moderately negatively with the TSBI. AI correlated with the TSBI slightly more than did AO, except on Emotional 
Table 4

Construct Validity: Correlations Between Actual-Self MFLs and BFI-44 Subscale Scores

\begin{tabular}{|c|c|c|c|c|c|c|c|c|c|c|}
\hline & \multicolumn{5}{|c|}{ MFL for actual self } & \multicolumn{5}{|c|}{ BFI-44 } \\
\hline & Sur & Agr & Con & $\mathrm{ESt}^{\mathrm{a}}$ & Int & Ext & Agr & Con & $\mathrm{Neu}^{\mathrm{a}}$ & Opn \\
\hline \multicolumn{11}{|l|}{ MFL for actual self } \\
\hline Surgency & - & & & & & & & & & \\
\hline Agreeableness & 25 & - & & & & & & & & \\
\hline Conscientiousness & 08 & 19 & - & & & & & & & \\
\hline Emotional Stability ${ }^{a}$ & 22 & 17 & 05 & - & & & & & & \\
\hline Intellect & -05 & -28 & -13 & -02 & - & & & & & \\
\hline \multicolumn{11}{|l|}{ BFI-44 } \\
\hline Extraversion & 52 & 17 & -04 & 15 & 05 & 88 & & & & \\
\hline Agreeableness & 15 & 52 & 02 & 13 & -20 & 18 & 83 & & & \\
\hline Conscientiousness & 11 & 00 & $\mathbf{5 0}$ & 08 & 01 & 06 & 12 & 81 & & \\
\hline Neuroticism $^{\mathrm{a}}$ & 16 & 16 & 00 & 39 & -03 & 29 & 33 & 11 & 83 & \\
\hline Openness & 06 & -01 & -11 & 06 & 37 & 17 & 09 & -01 & -05 & 78 \\
\hline
\end{tabular}

Note. $N=189$. Tabled values are zero-order Pearson correlation coefficients with decimal points omitted. Diagonal entries for BFI-44 are $(100 \times)$ Cronbach's $\alpha$ based on 192 cases with complete BFI-44 data.

${ }^{a}$ Neuroticism reversed for comparability with Emotional Stability.

Two-tailed $p$ values, Bonferroni-adjusted for 45 distinct tests: Italic indicates $p_{\text {Bon }}<.05$; boldface, $p_{\text {Bon }}<.001$. 
Stability. Among all self-discrepancy indices, Surgency AI correlated most negatively with TSBI social self-esteem, $r(179)=-.46, p_{\text {Bon }}<.001$.

Conventional global $S Q$ self-discrepancy. As in previous self-discrepancy research, the SQ-AI-SQ-AO correlation was strongly positive, $r(179)=$ $.59, p_{\text {Bon }}<.001$. Conventional SQ discrepancies were most convergently and discriminantly similar to Emotional Stability PBSDs and, especially, multidimensional PBSDs: For each of these two PBSDs, both convergent correlations (e.g., multidimensional AI with SQ-AI) were higher than both divergent correlations (e.g., multidimensional AI with SQ-AO). SQ discrepancies also correlated moderately with average PBSDs and weakly to moderately with Surgency, Agreeableness, and Conscientiousness PBSDs. None of these, however, showed clear convergent and discriminant patterns.

\section{DISCUSSION}

We have proposed and demonstrated a personality-based approach to self-discrepancy measurement, whereby self-beliefs and incongruities among their contents are examined within a FFM semantic framework. First, free-response self-beliefs were collected for three selves. Their content was then coded against the FFM and used to construct five MFLs, or personality scores, for each self, as well as several PBSD indices. We analyzed MFLs to test substantive self-discrepancy hypotheses and demonstrate the versatile operationalizations this strategy permits. Methodological sensitivity to the choice of an external factor analysis and to alternative content-weighting schemes was examined. Finally, MFL and PBSD construct validity were assessed against relevant criterion measures.

\section{Substantive Findings and Implications}

Below we highlight substantive self-discrepancy and personalitystructure findings that evidence the validity and versatility of this measurement strategy. Unless otherwise noted, remarks pertain to data and results based on Goldberg's (1990) factor analysis, although many hold for those based on Saucier's (1997) study as well. 
Table 5

Construct Validity: Correlations Between Personality-Based Self-Discrepancies and Depression, Self-Esteem, and Conventional Self-Discrepancy

\begin{tabular}{|c|c|c|c|c|c|}
\hline \multirow{2}{*}{$\begin{array}{l}\text { Self- } \\
\text { discrepancy } \\
\text { index }\end{array}$} & \multicolumn{2}{|c|}{ Depression } & \multirow{2}{*}{$\frac{\text { Self-esteem }}{\text { TSBI }}$} & \multicolumn{2}{|c|}{ Self-discrepancy } \\
\hline & BDI & CES-D & & SQ-AI & SQ-AO \\
\hline \multicolumn{6}{|c|}{ Actual-Ideal PBSD } \\
\hline $\mathrm{AI}_{\text {Sur }}$ & 21 & 18 & -46 & 27 & 14 \\
\hline $\mathrm{AI}_{\mathrm{Agr}}$ & 11 & 04 & -07 & 09 & 18 \\
\hline $\mathrm{AI}_{\mathrm{Con}}$ & -09 & 00 & 03 & 10 & 25 \\
\hline $\mathrm{AI}_{\mathrm{ESt}}$ & 20 & 20 & -17 & 37 & 28 \\
\hline $\mathrm{AI}_{\text {Int }}$ & -06 & -12 & 05 & 03 & 00 \\
\hline $\mathrm{AI}_{\text {Average }}$ & 21 & 18 & -35 & 43 & 43 \\
\hline $\mathrm{AI}_{\text {Euclidean }}$ & 16 & 13 & -26 & 62 & 41 \\
\hline \multicolumn{6}{|c|}{ Actual-Ought PBSD } \\
\hline $\mathrm{AO}_{\text {Sur }}$ & 15 & 18 & -35 & 20 & 10 \\
\hline $\mathrm{AO}_{\text {Agr }}$ & 06 & 03 & -02 & 07 & 11 \\
\hline $\mathrm{AO}_{\mathrm{Con}}$ & -05 & -01 & -07 & 16 & 22 \\
\hline $\mathrm{AO}_{\mathrm{ESt}}$ & 17 & 17 & -21 & 32 & 33 \\
\hline $\mathrm{AO}_{\text {Int }}$ & -01 & -04 & -03 & 06 & -11 \\
\hline $\mathrm{AO}_{\text {Average }}$ & 16 & 17 & -33 & 38 & 33 \\
\hline $\mathrm{AO}_{\text {Euclidean }}$ & 08 & 08 & -23 & 40 & 53 \\
\hline
\end{tabular}


Table 5 (cont.)

\begin{tabular}{|c|c|c|c|c|c|}
\hline \multirow{2}{*}{$\begin{array}{l}\text { Self- } \\
\text { discrepancy } \\
\text { index }\end{array}$} & \multicolumn{2}{|c|}{ Depression } & \multirow{2}{*}{$\frac{\text { Self-esteem }}{\text { TSBI }}$} & \multicolumn{2}{|c|}{ Self-discrepancy } \\
\hline & BDI & CES-D & & SQ-AI & SQ-AO \\
\hline \multicolumn{6}{|c|}{ Conventional SQ } \\
\hline SQ-AI & 30 & 19 & -38 & - & 59 \\
\hline SQ-AO & 17 & 17 & -30 & 59 & - \\
\hline
\end{tabular}


Self-discrepancy across, among, and within FFM personality dimensions. Our first primary hypothesis concerned the sample-level existence of mean self-discrepancies-that is, incongruities in typical selfbelief content among all three or between specific combinations of self domains. As the profile plots in Figure 1 depict graphically and the effect sizes in Table 2 express numerically, PBSDs clearly exist at the sample level, whether operationalized across (e.g., by combining multivariately or collapsing together) FFM dimensions or assessed on specific dimensions. The most direct PBSD test, the doubly multivariate MANOVA, yielded substantial effect sizes for all self-domain combinations. These effects reflect the considerable amount of variation in self-belief content attributable to incompatibility among selves. Note that in analyzing all FFM dimensions simultaneously, the MANOVA neither tests nor assumes equal MFL means or variances across the five factors, nor does it combine dimensions into a composite. Rather, dimensions are treated as separate but correlated, and self-discrepancy patterns on different dimensions cannot augment or cancel each other.

Profile parallelism hypotheses, which are central to establishing the value of PBSD measurement, require clarification: Although the term alludes to similar personality-profile shapes among domains, profile parallelism equivalently refers to similar self-discrepancy patterns among dimensions. Because parallelism holds if and only if the direction and magnitude of differences among selves are the same on all dimensions, the parallelism procedure tests both interpretations of the Domain $\times$ Dimension interaction. Hence, the moderate to large nonparallelism effect sizes attest to differential self-discrepancies among FFM dimensions. Much like interpreting a main effect in light of an interaction, considering only global self-belief incongruity in light of such nonparallelism would disregard discrepancy directions and magnitudes unique to each broad disposition.

This nonparallelism is not an artifact of either center or dispersion incommensurability among FFM dimensions. Some FFM dimensions (e.g., Agreeableness) exhibit clearly higher means than others (e.g., Intellect) when aggregated across self domains, as flatness tests verified.The parallelism test, however, asks specifically whether the personality profiles are shaped similarly for all selves, regardless of their flatness. Profile parallelism and aggregate or domain-specific profile flatness are independent matters both conceptually and statistically; one is neither necessary nor sufficient for the other. Furthermore, although 
dispersion incommensurability among scales could contribute artifactually to nonparallelism, this explanation can be ruled out on the basis of the 15 MFLs' relatively homogeneous dispersions (see Footnotes 11 and 14). Even if dimensions were not empirically commensurable, the disordinal interaction involving ideal and ought would be preserved under most reasonable monotonic transformations to commensurability (e.g., dividing MFLs on each dimension by some variability measure pooled across self domains). In short, self-discrepancy similarity among FFM dimensions is untenable.

Because the empirical nature of self-discrepancies depends upon whether and how FFM content is incorporated, we now consider practical and substantive implications of this personality-based strategy. First, collapsing self-belief content across FFM dimensions essentially weights all content aspects equally, which reduces sensitivity to discrepancies among selves. For example, ideal and ought MFLs were consistently higher than actual MFLs, which coincides with the notion of selfregulatory standards being more self-descriptively extreme than our self-concept content. Consequently, discrepancy between the actual self and any self-guide obtained even when personality dimensions were combined. Nevertheless, because discrepancy magnitudes vary among dimensions, these level discrepancies on the composite personality score were notably smaller than their corresponding MANOVA effects, which incorporate variability on and covariability among content dimensions (see Table 2).

The IO discrepancy illustrates nicely the consequences of neglecting dimension-specific self content. The last column of univariate effect sizes in Table 2 indicates weak to moderate IO discrepancy on all five dimensions. However, as the means in Table 1 and Figure 1 show, the ought self-guide is higher than ideal (i.e., ought represents the higher standard) on Agreeableness and Conscientiousness, whereas ideal is higher on Surgency, Emotional Stability, and Intellect. This variation in self-guide dominance was reflected in the IO parallelism contrast, which yielded the largest of all specific self-domain nonparallelism effects. Furthermore, the MANOVA results indicate substantial collective IO discrepancy. All these procedures distinguish among semantic dimensions, and all detect IO discrepancy in one direction or another. In stark contrast, the level-coincidence test indicates that the two self-guides are indistinguishable. The level-coincidence procedure, of course, allowed differential IO effects to cancel each other in the composite discrepancy. Might 
these differential self-guide discrepancies relate to past empirical difficulty distinguishing between ideal and ought and, by extension, between $\mathrm{AI}$ and $\mathrm{AO}$ ? Although mean level-coincidence and high AI-AO correlation are different issues, it is tempting to speculate that the two are related and might both be illuminated by attending to explicit semantic dimensions.

Second, considering personality dimensions collectively by summarizing self-discrepancy in a single index, even with a multivariate procedure, takes only limited advantage of the versatility and rich descriptive and explanatory potential of the personality-based approach. Collective, global discrepancy for any self-domain combination includes some dimensions on which the selves differ less (e.g., Agreeableness and Conscientiousness for AI, Surgency and Intellect for AO, Intellect for $\mathrm{A}[\mathrm{IO}]$, and Emotional Stability for $\mathrm{IO}$ ), thereby attenuating the measured impact of dispositions that are more important to the discrepancy.

Also, specific dimensions can reveal potentially interesting distinctions. For instance, different incongruities dominate each trait: AI is greater than AO on Surgency, Emotional Stability, and Intellect, whereas AO dominates on Agreeableness and Conscientiousness. What do these two self-discrepancy patterns suggest about personality's role in selfbelief incongruity? McCrae and John's (1992) suggestion that Agreeableness and Conscientiousness share a highly evaluative component may explain their common domination by ought self-beliefs. Perhaps typical college students perceive dispositional shortcomings with respect to Surgency (e.g., being self-conscious and shy vs. humorous and outgoing - the most frequently listed attributes with negative vs. positive primary loadings on Surgency), Emotional Stability (sensitive, moody vs. optimistic, patient), and Intellect (gullible, submissive vs. intelligent, independent) as failures to attain their desires, hopes, or aspirations, so that exhibiting these negative traits reflects the absence of positive outcomes. On the other hand, shortcomings with respect to Agreeableness (stubborn, self-centered vs. honest, friendly) and Conscientiousness (lazy, selfish vs. responsible, reliable) may represent failures to follow rules or to fulfill obligations or prescribed duties, and reflect the presence of negative outcomes. Clearly, viewing self-discrepancies collectively or globally obscures these distinct dispositional contributions.

FFM personality structure across, among, and within self domains. The MFL means in Table 1 and Figure 1 also represent FFM personality 
structure across, among, and within self domains. Analytic procedures concerning phenotypic personality structure were largely exploratory, aimed primarily at demonstrating the versatility of MFL scores. Personality structure across selves was addressed by the omnibus flatness test and follow-up contrasts comparing each personality dimension to the other four. When distinct self-beliefs are aggregated, some personality aspects are more self-descriptive than others. Agreeableness is by far the most self-descriptive, whereas Emotional Stability and Intellect are least self-descriptive.

Substantive interpretations of and explanations for this variation in self-descriptiveness among FFM dimensions remain open matters. Although it may simply reflect trait-representation variability in Goldberg's (1990) 1,710 pool, the pattern of MFL means is inconsistent with the pattern of near-zero factor loadings averaged across the 1,710 attributes: $.002, .002, .003, .005$, and .001, respectively, on Surgency, Agreeableness, Conscientiousness, Emotional Stability, and Intellect. Furthermore, MFL nonflatness does not likely arise simply from methodological artifacts of either the factor analysis, MFL construction, or both (see Footnote 9). Instead, we presume that traits vary in their frequency or degree of representation in the self-descriptive lexicon used by laypersons. Consistent with this explanation, the pattern of factor loading averages for respondents' 874 SQ attributes—274 matching Goldberg's pool and 600 coded by judges (3,404 and 1,423 when weighted by SQ frequency)—more closely resembles that for MFLs: .058, .110, .064, .043 , and $.046(.081, .192, .101, .056$, and .060 , weighted). The FFM content of respondents' self-beliefs tended to fall toward the positive poles of all dimensions, and this tendency was stronger for some dispositions (e.g., Agreeableness) than for others (e.g., Emotional Stability and Intellect). Whether trait desirability, familiarity, importance, or salience can explain this variation in trait self-descriptiveness remains a topic for future research.

The more interpretable finding is that actual, ideal, and ought personality structures differ markedly, as demonstrated by the parallelism tests and flatness follow-ups. For example, Agreeableness was most descriptive for all selves, but especially for the ought domain, and Emotional Stability was least descriptive for the actual domain. This personalitystructure discrepancy among selves suggests possible functional significance of and interactions among broad personality traits in self-regulation. Might certain combinations of broad dispositions 
contribute differentially to certain self-regulatory processes? Might certain configurations of one's self-concept and one or more self-guides in semantic personality space predict certain emotional vulnerabilities? Investigating these questions with a systemic approach to self-discrepancy measurement would seem most profitable.

Construct validity of personality-based measures. The moderate convergence between BFI-44 scores and self-concept MFLs from the SQ needs explanation. Low MFL reliability-which is problematic to assess-would diminish convergence. Also, convergence would be attenuated to the extent that BFI-44 items do not map onto the semantic content of Goldberg's (1990) factor analysis; this is particularly pertinent to Intellect/Openness, given its instability across studies (McCrae \& John, 1992) and difficulty constructing its BFI-44 subscale (John et al., 1991). The free-response versus fixed-item formats may contribute additional method variance. Specifically, SQ-based MFLs may reflect one's personally important and accessible self-beliefs only. The MFL-BFI-44 correlation would be attenuated insofar as the personality content of one's important, accessible self-beliefs differs from that of less important, less accessible self-beliefs tapped by less personally relevant BFI-44 items.

Self-discrepancy theory's predictions about distinct AI and AO relations with dejection were not supported using the BDI and CES-D. As Higgins (1987) has noted, however, neither depression instrument distinguishes dejection- from agitation-related depression. Also, we examined zero-order correlations rather than the first- and higher-order partial and semi-partial correlations Higgins and his colleagues often report. PBSD unreliability also would attenuate correlations with BDI and CES-D dejection-related content. Lack of discriminant relations aside, depression was most associated with PBSDs on Surgency and Emotional Stability, which suggests that these dispositions may play self-regulatory roles in emotional discomfort.

The moderately negative PBSD-TSBI correlations, which were somewhat stronger for AI than for AO, replicated Higgins' (1987) self-esteem findings. Moreover, TSBI social self-esteem was predicted better by Surgency AI than by any other discrepancy index. This demonstrates the predictive potential of disposition-specific PBSDs for specific affective and motivational outcomes. On a related note, Tangney et al.'s (1998) failure to find discriminant self-discrepancy relations between shame and guilt using the conventional SQ might be reexamined gainfully using a 
personality-based coding strategy, which permits such connections with previous research.

\section{Methodological Issues}

Measurement advantages. Our proposed FFM-based strategy for selfdiscrepancy measurement offers three primary strengths. First, following Hoelter's (1985b) recommendations for systemic self-conception measurement, the strategy incorporates meaningful self-belief dimensions explicitly into personality (MFL) and self-discrepancy (PBSD) scores. Second, in keeping with principles underlying self-discrepancy theory, self-beliefs are collected using a free-response procedure that elicits relatively important and accessible attributes. Third, coding SQ attributes against externally defined personality content is efficient, in that it yields three five-dimensional personality profiles using at most 30 freeresponse attributes from each individual.

Methodological sensitivity. The sensitivity of personality-structure findings to the Goldberg- versus Saucier-based coding scheme likely reflects differences in factor definitions. It is not surprising that Saucier's (1997) item pool, based on item familiarity, yielded factors with different semantic definitions. Also, our using five of Saucier's seven factors neglected the trait content of attributes with substantial loadings on the sixth and seventh factors. Nevertheless, the relatively high and low aggregate MFLs on Agreeableness/Kindness and Intellect, respectively, held for both the Goldberg- and Saucier-based analyses, which provides converging evidence for these dispositions' relative standings among important self-beliefs. Furthermore, and most central to our proposed strategy, the robustness of self-discrepancy findings to this methodological alteration demonstrates that PBSD effects-particularly nonparallelism-are more than merely artifacts specific to Goldberg's (1990) item pool and factoring procedures.

Regarding the choice of semantic weights, constructing MFLs from raw factor loadings is but one defensible approach. Statistical and empirical properties of factor-analytic results and MFL personality scores constructed therefrom should be considered carefully. Our examinations of discretized and salient loadings have satisfied us that, in line with Wainer's (1976) assertions about linear combinations, most reasonable ways of specifying the direction and gross magnitude of weights yield 
similar MFLs. We anticipate, however, exploring other alternatives in two recently collected SQ data sets, such as the AB5C circumplex projections (Hofstee et al., 1992) suggested by reviewers, or unit-weight factor-score approximations (Gorsuch, 1983, pp. 266-270).

Idiographic versus nomothetic assessment. Our proposed strategy and the conventional SQ approach use the same method to collect self-beliefs. Whereas the conventional approach is typically considered idiographic, some might consider our personality-based strategy nomothetic because it defines self-belief content against an external, normative factor analysis (see Footnotes 4, 5, and 8). Consider, however, a coder using Roget's Thesaurus to operationalize semantic content (i.e., synonymity and antonymity) by the conventional SQ approach. Goldberg's results and the thesaurus are both normative, in that response meaning is derived from semantic associations typical for some group. Goldberg's factor results, derived from late-20th-century college students rating the selfdescriptiveness of trait adjectives, seems a particularly apt semantic standard for estimating the personality content of participants' selfdescriptive attributes. By comparison, it is unclear how term meanings are derived for a lexicographic compilation such as Roget's Thesaurus, and the population of persons to whom these meanings generalize is ambiguous.

Truly idiographic self-discrepancy assessment goes beyond choosing the least normative semantic standard. Higgins's (1987) exposition of self-discrepancy theory makes clear that one's personally relevant, important, and accessible self-discrepancies most impact one's self-regulatory consequences. Insofar as this is true, self-discrepancy assessment that reflects an individual's implicit, subjective conceptualization of self-belief content should uphold the theory's predictions most strongly. The challenging problem is to estimate subjective distances among personally relevant self-conceptions accurately and precisely. Optimal approaches may lie between our proposed strategy and more sophisticated but data-intensive methods such as those advanced by Hoelter (1985b) and Hart et al. (1997).

Alternative statistical procedures. Our MFL analyses primarily tested hypotheses about sample-level mean self-discrepancies and personality structure. Similar analyses could include additional relevant predictors or covariates, such as clinical depression level, parenting status, or drug 
use history. Data generated by this approach also could operationalize more complex self-belief patterns like those Higgins, Vookles, and Tykocynski (1992) found to predict emotional and physical problems. Furthermore, MFLs can be combined into PBSDs or other personality-based scores using various combinations of self domains and personality dimensions, and can be used as predictors or outcomes in further analyses. The construct-validity analyses above illustrate a few such options. Other multivariate procedures, such as configural frequency analysis, discriminant analysis, and clustering procedures might also facilitate insights into the alignments of selves in personality space.

\section{Future Directions}

Substantive directions. Endeavors to understand the roles of dispositions in self-discrepancies might benefit from the proposed strategy. Why, for instance, are depression, self-esteem, and global self-discrepancies most correlated with Emotional Stability and Surgency discrepancies? Considering lay conceptualizations of Surgency and Emotional Stability in terms of self-regulatory goals with a promotion versus a prevention focus (Higgins, Shah, \& Friedman, 1997) might provide insight into these relations. Why is Agreeableness consistently the most self-descriptive dimension? Graziano and Eisenberg's (1997) summary of theoretical conceptualizations of Agreeableness may suggest an answer. Moreover, one might speculate about correlates of certain dispositional discrepancies in certain contexts. For instance, social self-esteem relates specifically to Surgency AI; shyness might behave similarly, whereas social anxiety is perhaps associated distinctly with Surgency AO.

Past self-discrepancy research could be reexamined or replicated within a personality framework. For instance, certain trait discrepancies may predict emotional distress for new parents (Alexander \& Higgins, 1993), whereas others may underlie the relation between discrepancy and drug addicts' affective responses (Avants et al., 1993). Boggiano and Barrett (1991) found sex differences in SQ ideal content, such that females listed more attractiveness and interpersonal attributes whereas males listed more success attributes. Perhaps sex or gender moderates the role of certain content dimensions in certain discrepancies. Explanations for these and other PBSD phenomena could clarify the role of broad 
personality traits in our self-concept, self-guide, and self-regulatory patterns.

Methodological directions. Alternative personality-based data collection and coding strategies are conceivable. The content-based approach we have proposed could certainly be extended beyond Goldberg's factor analysis to other FFM factor analyses (e.g., Saucier, 1997), other operationalizations of personality description (e.g., the AB5C; Hofstee et al., 1992), or other profitable semantic frameworks tailored to specific theoretical interests. The general approach essentially requires methods for collecting one's important self-beliefs and for locating the content of each belief along one or more semantic dimensions. Beliefs might be located by factoring collected responses in the same or a separate study, having respondents generate a collective or individual semantic space via multidimensional scaling methods, or asking judges or experts to sort attributes or rate them along one or more predetermined semantic dimensions. Possible criteria for identifying optimal methods of selfdiscrepancy assessment for certain purposes include convergence with one or more gold-standard self-discrepancy measures and with theoretically related constructs, as well as practical implementation considerations. Multitrait-multimethod (Kenny \& Kashy, 1992) and interbattery factor analysis (Finch, Panter, \& Caskie, 1999; Tucker, 1973) techniques seem particularly well-suited for these challenges.

\section{Conclusions}

Our findings lead us to conclude that a FFM personality framework applied to free-response self-descriptions can aptly characterize the content of self-beliefs and incongruities among them. Self-discrepancies obtain across, among, and within personality dimensions by various operationalizations, and their nature depends upon the incorporation of FFM semantic information. The existence, direction, and magnitude of a particular self-discrepancy depend on (a) whether it is assessed on a single FFM dimension or on several dimensions, (b) which single dimension is considered if the former, and (c) how several dimensions are combined-multivariately or by averaging-if the latter. Furthermore, this operationalization of phenotypic personality structure reveals different profiles of trait descriptiveness for different self-belief domains. In view of these personality-based findings, their robustness to methodological 
adjustments, and initial evidence of construct validity, we contend that incorporating personality structure into the assessment of self-belief congruity offers substantive advantages. It is our hope that the present methodology will stimulate integrative inquiry toward a richer, more articulated description and understanding of personality and the self.

\section{REFERENCES}

Alexander, M. J., \& Higgins, E. T. (1993). Emotional trade-offs of becoming a parent: How social roles influence self-discrepancy effects. Journal of Personality and Social Psychology, 65, 1259-1269.

Anderberg, M. R. (1973). Cluster analysis for applications. New York: Academic Press.

Avants, S. K., Singer, J. L., \& Margolin, A. (1993). Self-representations and negative affect in cocaine-dependent individuals. Imagination, Cognition and Personality, 13, 3-24.

Beck, A. T., Steer, R. A., \& Garbin, M. G . (1988). Psychometric properties of the Beck Depression Inventory: Twenty-five years of evaluation. Clinical Psychology Review, 8, 77-100.

Beck, A. T., Ward, C. H., Mendelson, M., Mock, J., \& Erbaugh, J. (1961). An inventory for measuring depression. Archives of General Psychiatry, 4, 561-571.

Block, J. (1971). Lives through time. Berkeley, CA: Bancroft.

Block, J. (1978). The Q-sort method in personality assessment and psychiatric research. Palo Alto, CA: Consulting Psychologists Press. (Original work published 1961)

Block, J. (1995a). A contrarian view of the five-factor approach to personality description. Psychological Bulletin, 117, 187-215.

Block, J. (1995b). Going beyond the five factors given: Rejoinder to Costa and McCrae (1995) and Goldberg and Saucier (1995). Psychological Bulletin, 117, 226-229.

Boggiano, A. K., \& Barrett, M. (1991). Gender differences in depression in college students. Sex Roles, 25, 595-605.

Breckler, S. J., Pratkanis, A. R., \& McCann, C. D. (1991). The representation of self in multidimensional cognitive space. British Journal of Social Psychology, 30, 97-112.

Cohen, J., \& Cohen, P. (1983). Applied multiple regression/correlation analysis for the behavioral science (2nd ed.). Hillsdale, NJ: Erlbaum.

Costa, P. T., Jr., McCrae, R. R., \& Dye, D. A. (1991) Facet scales for Agreeableness and Conscientiousness: A revision of the NEO Personality Inventory. Personality and Individual Differences, 12, 887-898.

Cox, T. F., \& Cox, M. A. A. (1994). Multidimensional scaling. London: Chapman \& Hall.

Cudeck, R., \& O’Dell, L. L. (1994). Applications of standard error estimates in unrestricted factor analysis: Significance tests for factor loadings and correlations. Psychological Bulletin, 115, 475-487.

Donahue, E. M., Robins, R. W., Roberts, B. W., \& John, O. (1993). The divided self: Concurrent and longitudinal effects of psychological adjustment and social roles on self-concept differentiation. Journal of Personality and Social Psychology, 64, 834-846. 
Finch, J. F., Panter, A. T., \& Caskie, G. I. L. (1999). Two approaches for identifying shared personality dimensions across methods. Journal of Personality, 67, 407-438.

Flora, D. B., Panter, A. T., \& Hafdahl, A. R. (1998, August). Measurement of personalitybased self-discrepancies using personality instruments. Poster session presented at the annual meetings of the American Psychological Association, San Francisco, CA.

Forston, M. T., \& Stanton, A. L. (1992). Self-discrepancy theory as a framework for understanding bulimic symptomatology and associated distress. Journal of Social and Clinical Psychology, 11, 103-118.

Goldberg, L. R. (1982). From Ace to Zombie: Some explorations in the language of personality. In C. D. Spielberger \& J. N. Butcher (Eds.), Advances in personality assessment (Vol. 1, pp. 203-234). Hillsdale, NJ: Erlbaum.

Goldberg, L. R. (1990). An alternative "description of personality": The Big-Five factor structure. Journal of Personality and Social Psychology, 59, 1216-1229.

Goldberg, L. R. (1992). The development of markers of the Big-Five factor structure. Psychological Assessment, 4, 26-42.

Gorsuch, R. L. (1983). Factor analysis (2nd ed.). Hillsdale, NJ: Erlbaum.

Gramzow, R. H., Sedikides, C., Panter, A. T., \& Insko, C. A. (in press). Aspects of self-regulation and self-structure as predictors of perceived emotional distress. Personality and Social Psychology Bulletin.

Graziano, W. G., \& Eisenberg, N. (1997). Agreeableness: A dimension of personality. In R. Hogan, J. Johnson, \& S. Briggs (Eds.), Handbook of personality psychology (pp. 795-824). San Diego, CA: Academic Press.

Hafdahl, A. R., Panter, A. T., Gramzow, R. H., Sedikides, C., \& Insko, C. A. (1998, August). Construct validity of personality-based self-discrepancy indices and analogues. Poster session presented at the annual meetings of the American Psychological Association, San Francisco, CA.

Hart, D., Field, N. P., Garfinkle, J. R., \& Singer, J. L. (1997). Representations of self and other: A semantic space model. Journal of Personality, 65, 77-105.

Helmreich, R., \& Stapp, J. (1974). Short forms of the Texas Social Behavior Inventory (TSBI), an objective measure of self-esteem. Bulletin of the Psychonomic Society, 4, 473-475.

Higgins, E. T. (1987). Self-discrepancy: A theory relating self and affect. Psychological Review, 94, 319-340.

Higgins, E. T. (1996). The "self-digest": Self-knowledge serving self-regulatory functions. Journal of Personality and Social Psychology, 71, 1062-1083.

Higgins, E. T., Bond, R. N., Klein, R., \& Strauman, T. (1986). Self-discrepancies and emotional vulnerability: How magnitude, accessibility, and type of discrepancy influence affect. Journal of Personality and Social Psychology, 51, 5-15.

Higgins, E. T., Klein, R., \& Strauman, T. (1985). Self-concept discrepancy theory: A psychological model for distinguishing among different aspects of depression and anxiety. Social Cognition, 3, 51-76.

Higgins, E. T., Shah, J., \& Friedman, R. (1997). Emotional responses to goal attainment: Strength of regulatory focus as moderator. Journal of Personality and Social Psychology, 72, 515-525.

Higgins, E. T., Van Hook, E., \& Dorfman, D. (1988). Do self-attributes form a cognitive structure? Social Cognition, 6, 177-207. 
Higgins, E. T., Vookles, J., \& Tykocinski, O. (1992). Self and health: How “patterns" of self-beliefs predict types of emotional and physical problems. Social Cognition, 10, $125-150$.

Hoelter, J. W. (1985a). A structural theory of personal consistency. Social Psychology Quarterly, 48, 118-129.

Hoelter, J. W. (1985b). The structure of self-conception: Conceptualization and measurement. Journal of Personality and Social Psychology, 49, 1392-1407.

Hofstee, W. K. B., de Raad, B., \& Goldberg, L. R. (1992). Integration of the Big Five and circumplex approaches to trait structure. Journal of Personality and Social Psychology, 63, 146-163.

Houston, D. A. (1990). Empathy and the self: Cognitive and emotional influences on the evaluation of negative affect in others. Journal of Personality and Social Psychology, 59, 859-868.

John, O. P., Donahue, E. M., \& Kentle, R. L. (1991). The “Big Five” Inventory-Versions $4 a$ and 54. Berkeley, CA: Institute of Personality Assessment and Research.

Johnson, R. A., \& Wichern, D. W. (1992). Applied multivariate statistical analysis (3rd ed.). Englewood Cliffs, NJ: Prentice Hall.

Kenny, D. A, \& Kashy, D. A. (1992). Analysis of the multitrait-multimethod matrix by confirmatory factor analysis. Psychological Bulletin, 112, 165-172.

Kupersmidt, J. B., Buchele, K. B., Voegler, M. E., \& Sedikides, C. (1996). Social self-discrepancy: A theory relating peer relations problems and school maladjustment. In J. Juvonen \& K. Wentzel (Eds.), Social motivation: Understanding children's school adjustment (pp. 66-97). Cambridge, MA: Cambridge University Press.

Linville, P. W. (1987). Self-complexity as a cognitive buffer against stress-related illness and depression. Journal of Personality and Social Psychology, 52, 663-676.

Markus, H., \& Nurius, P. (1986). Possible selves. American Psychologist, 41, 954-969.

Maxwell, S. E., \& Delaney, H. D. (1990). Designing experiments and analyzing data: A model comparison perspective. Belmont, CA: Wadsworth.

McAdams, D. P. (1992). The five-factor model in personality: A critical appraisal. Journal of Personality, 60, 329-361.

McAdams, D. P. (1995). What do we know when we know a person? Journal of Personality, 3, 364-396.

McCrae, R. R., \& Costa, P. T., Jr. (1997). Personality trait structure as a human universal. American Psychologist, 52, 509-516.

McCrae, R. R., \& John, O. P. (1992). An introduction to the five-factor model and its applications. Journal of Personality, 60, 175-215.

Mikulincer, M., \& Peer-Goldin, I. (1991). Self-congruence and the experience of happiness. British Journal of Social Psychology, 30, 21-35.

Radloff, L. S. (1977). The CES-D Scale: A self-report depression scale for research in the general population. Applied Psychological Measurement, 1, 385-401.

Roney, C. J. R., \& Sorrentino, R. M. (1995). Reducing self-discrepancies or maintaining self-congruence? Uncertainty orientation, self-regulation, and performance. Journal of Personality and Social Psychology, 68, 485-497.

Sánchez-Bernardos, M. L., \& Sanz, J. (1992). Effects of the discrepancy between self-concepts on emotional adjustment. Journal of Research in Personality, 26, 303-318. 
Saucier, G. (1997). Effects of variable selection on the factor structure of person descriptors. Journal of Personality and Social Psychology, 73, 1296-1312.

Scott, L., \& O'Hara, M. W. (1993). Self-discrepancies in clinically anxious and depressed university students. Journal of Abnormal Psychology, 102, 282-287.

Sedikides, C. (1995). Central and peripheral self-conceptions are differentially influenced by mood: Tests of the differential sensitivity hypothesis. Journal of Personality and Social Psychology, 69, 759-777.

Sedikides, C., \& Strube, M. J. (1997). Self-evaluation: To thine own self be good, to thine own self be sure, to thine own self be true, and to thine own self be better. In M. P. Zanna (Ed.), Advances in experimental social psychology (Vol. 29, pp. 209-269). New York: Academic Press.

Sheeran, P., \& McCarthy, E. (1992). Social structure, self-conception and well-being: An examination of four models with unemployed people. England Journal of Applied Social Psychology, 22, 117-133.

Stevens, J. (1996). Applied multivariate statistics for the social sciences. Mahwah, NJ: Erlbaum.

Strauman, T. J. (1990). Self-guides and emotionally significant childhood memories: A study of retrieval efficacy and incidental negative emotional content. Journal of Personality and Social Psychology, 59, 869-880.

Strauman, T. J. (1992). Self-guides, autobiographical memory, and anxiety and dysphoria: Toward a cognitive model of vulnerability to emotional distress. Journal of Abnormal Psychology, 101, 87-95.

Strauman, T. J., \& Higgins, E. T. (1988). Self-discrepancies as predictors of vulnerability to distinct syndromes of chronic emotional distress. Journal of Personality, 56, 685-707.

Tangney, J. P., Niedenthal, P. M., Covert, M. V., and Barlow, D. H. (1998). Are shame and guilt related to distinct self-discrepancies? A test of Higgins's (1987) hypotheses. Journal of Personality and Social Psychology, 75, 256-268.

Tatsuoka, M. M. (1988). Multivariate analysis: Techniques for educational and psychological research (2nd ed.). New York: Macmillan.

Tucker, L. R. (1973). An inter-battery factor analytic approach to linear predictive systems. Educational \& Psychological Measurement, 33, 77-97.

Tykocinksi, O., Higgins, E. T., \& Chaiken, S. (1994). Message framing, self-discrepancies, and yielding to persuasive messages: The motivational significance of psychological situations. Personality and Social Psychology Bulletin, 20, 107-115.

Wainer, H. (1976). Estimating coefficients in linear models: It don't make no nevermind. Psychological Bulletin, 83, 213-217.

Young, F. W., \& Hamer, R. M. (1987). Multidimensional scaling: History, theory, and applications. Hillsdale, NJ: Erlbaum.

\section{Appendix}

Constructing Goldberg-Based Mean Factor Loading Scores

Responses to each completed Selves Questionnaire (SQ) comprised from 1 to 10 open-ended self-descriptive attributes (a word or short phrase) 
listed for each self domain (actual, ideal, ought); extent ratings were collected but not used for the coding procedure described here. This appendix describes how loadings from Goldberg's (1990) factor analysis (see Footnote 4) were used to construct a score on each FFM personality dimension (Surgency, Agreeableness, Conscientiousness, Emotional Stability, Intellect) for each self domain.

\section{Judging Non-Matches}

The 191 respondents' 4,861 original attributes were reduced to 901 unique terms. Of these, 274 (30.4\%) were matches (attributes strictly identical to one of Goldberg's 1,710 trait adjectives; e.g., devout, feminine, hardworking, intelligent, introverted, outgoing, and smart) that accounted for 3,404 (70.0\%) of the original attributes. The 627 nonmatches (e.g., devoted, good Christian, ladylike/feminine, hard worker, more intelligent, smart/intelligent, introvert, and not outgoing) required additional processing.

Each of two independent judges - a senior undergraduate psychology major and a graduate student in psychology—-worked with a list of all nonmatches in a different randomized order. Judges identified a synonymous trait adjective for each nonmatch and indicated the degree of similarity between each nonmatch and its synonym from 1 (slightly similar) to 3 (very similar). Judges were allowed not to choose a synonym. Of the 627 nonmatches, $27(4.3 \%)$ were uncoded by both judges; $28(4.5 \%)$, by the first judge only; and $51(8.1 \%)$, by the second judge only. Based on synonyms for the $521(83.1 \%)$ nonmatches coded by both judges, interrater reliability (treating loadings as ratings) as indexed by the intraclass correlation coefficient (ICC) was .68, .64, .73, .69, and .67 for Surgency, Agreeableness, Conscientiousness, Emotional Stability, and Intellect, respectively. This level of agreement is respectable, given that many nonmatches reflected content excluded deliberately from Goldberg's trait pool, such as physical descriptors and social status terms.

Two trait adjectives whose averaged loadings capture the FFM content of a particular nonmatch might have very different loadings themselves, which would attenuate ICC-indexed agreement. In an auxiliary study of judges' ability to reproduce Goldberg's loadings, four judges completed a similar synonym task for each of 100 random Goldberg trait adjectives; the only changes were a 9-point similarity scale and a reduced synonym 
pool of 1,610 Goldberg trait adjectives. Except on Intellect, judges' averaged loadings for the 93 adjectives for which at least one judge chose a synonym reproduced Goldberg loadings rather well, ICC $=.86, .84$, $.77, .70$, and .50 . Note, however, that these trait adjectives likely represented FFM content better than did the nonmatches.

One alternative to judging nonmatches would be to omit them, which effectively asserts that each attribute loads equally on all factors and all loadings are zero. Also, any association of one's propensity to generate nonmatches with one's self-belief content or affective state would tend to confound the measurement procedure with outcome constructs. We are currently addressing these free-response coding issues.

\section{Factor-Loading Assignment}

Each matching attribute was simply assigned the loading on each of the five factors for the corresponding Goldberg trait adjective. For instance, loadings for determined, in order of the factors listed above, were .23, $.17, .32, .06$, and .06 . Coding nonmatches depended upon judges' selections of synonymous adjectives:

1. When both judges identified a synonym for the attribute, each of the attribute's five "factor loadings" was computed by averaging the two synonyms' corresponding loadings. For instance, judges chose humorous $(.28, .00,-.09, .13,-.01)$ and jaunty $(.27,-.01$, $-.11,-.04, .02)$ as synonyms for funny/amusing, which was thus assigned the loadings $.28,-.01,-.10, .05$, and .01 .

2. When only one judge identified a synonym, the factor loadings associated with that judge's synonym were used as factor loadings for the attribute. For instance, nonconventional was assigned the loadings of its single synonym, nonconforming: .01, -.12,-.19, .05, and .17 .

3. When neither judge identified a synonym, the attribute was not codable and was omitted from further computations.

By this procedure, all codable attributes were assigned five factor loadings. 


\section{Mean Factor Loading Score Computation}

Fifteen Goldberg-based mean factor loading scores (MFLs) were computed for each respondent: five for each of three self domains. Within a particular self domain, each MFL was computed as the arithmetic mean of the corresponding factor loadings across all codable attributes in that self domain. For example, suppose a respondent listed the following eight attributes for the actual self domain: jealous, nonconventional, funny/amusing, caring, determined, empathetic, financially secure, and somewhat moody. All of these except financially secure are codable against the Goldberg 1,710. Surgency loadings (from matches or judged synonyms) for the seven codable attributes are $.07, .01, .28, .21, .23, .04$ and -.19 . This respondent's actual Surgency MFL would be the average of these seven loadings, $.0929 \approx .09$. 